\title{
Infactus Gravid Cerebral: about a Case at the Maternity Hospital of the Regional of Niamey
}

\author{
Soumana Diaouga $\mathrm{H}^{1^{*}}$, Djibrilla Almoustapha $\mathrm{A}^{2}$, Mahamadou $\mathrm{G}^{1}$, Nafiou $\mathrm{I}^{1}$, Nayama $\mathrm{M}^{3}$, Garba $\mathrm{M}^{3}$ \\ ${ }^{1}$ Department of Obstetric Gynecology, Maternity of the Regional Hospital Center of Niamey, Niger \\ ${ }^{2}$ Department of Hematology, Niamey National Hospital, Niamey, Niger \\ ${ }^{3}$ Department of Obstetric Gynecology, Issaka Gazobi Maternity of Niamey, Niger
}

DOI: $\underline{10.36348 / \mathrm{sjpm} .2020 . \mathrm{v} 05 \mathrm{i} 03.008}$

| Received: 29.02.2020 | Accepted: 07.03.2020 | Published: 21.03.2020

*Corresponding author: Soumana Diaouga Hamidou

\section{Abstract}

A stroke stroke is extremely rare during pregnancy. Called PRA, the prognosis is potentially serious, the mechanism of occurrence and causes are still uncertain. Neurologic manifestations in a gestational setting associated with other risk factors may be life-threatening for the mother and fetus by further complicating the choice of treatment. We report the observation of a young woman pregnant with $26 \mathrm{SA}+4 \mathrm{jrs}$ in anemia led to the diagnosis of a cerebral infarction.

Keywords: Pregnancy stroke, maternity CHR, Niamey Niger.

Copyright @ 2020: This is an open-access article distributed under the terms of the Creative Commons Attribution license which permits unrestricted use, distribution, and reproduction in any medium for non-commercial use (NonCommercial, or CC-BY-NC) provided the original author and sources are credited.

\section{INTRODUCTION}

Cerebro vascular Stroke (CVS) is a focal neurological deficit resulting from ischemic or haemorrhagic involvement of the cerebral blood vessels. Its occurrence during the pregnancy is extremely rare, it varies from 4 - 36/100 000 for cerebral infarction [1]. However, pregnancy is considered a risk factor for ischemic or haemorrhagic stroke. An increase in the number of hospitalizations for stroke-GP between 1994 and 2007 was observed in the United States, nearly $50 \%$ for gestational stroke and $83 \%$ for postpartum stroke [2]. Physiological changes that may increase the risk of vascular events during pregnancy: state of maximum hypercoagulability approaching the term, increased cardiac output and total blood volume, and altered arterial media structure [3]. The clinical manifestations are dominated by the neurological signs and the diagnosis is made by the MRI or the brain scanner in a context of pregnancy [4]. Potentially dramatic by the risk of disability and death in the mother and the possible consequences in the child. Numerous uncertainties remain regarding the incidence of these strokes, their risk factors and their causes, maternal and fetal prognosis as well as obstetric and neurological management $[1,5]$. We report a rare case of pregnancy-related stroke in a young subject, diagnosed at the maternity ward of the CHR of Niamey.

\section{OBSERVATION}

This was a 24-year-old patient, sixth gesture and five previous parities with a history of two caesareans, without any notion of hypertension or diabetes, admitted in our service for motor deficit of sudden occurrence in a context not febrile and nontraumatic, with a pregnancy of $26 \mathrm{SA}+4 \mathrm{j}$ of gestational age. The clinical examination found a conscious patient (Glasgow: 15/15), the conjunctiva and the mucous membranes were pale, an arterial tension (TA) at $110 / 70 \mathrm{mmHg}$ in both arms, a temperature at $37^{\circ} \mathrm{C}$, chronic headaches in helmet calmed by the usual analgesics. Paroxysmal motor disorders and sudden Broca aphasia 24 hours before admission.

The physical examination found a disproportionate right hemiplegia: muscular strength rated at $0 / 5$ and $1 / 5$ respectively at the lower and upper right limbs. The obstetrical examination was without particularity.

The brain scan performed at $72 \mathrm{H}$ post-deficit revealed a left capsular ischemic stroke (Figure 1 and 2). 

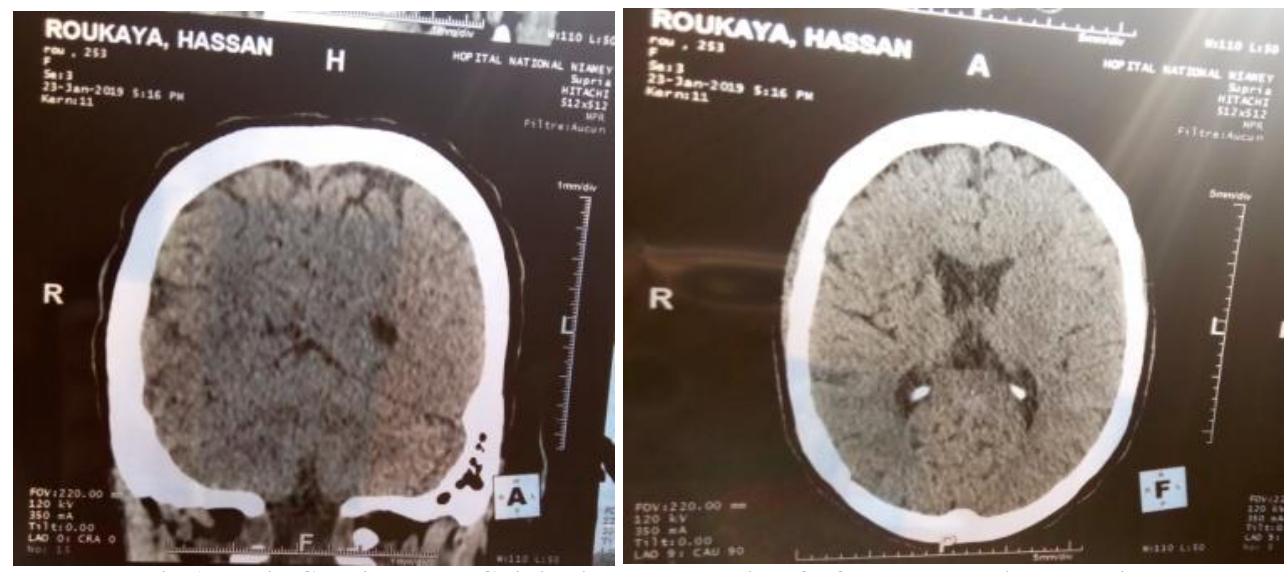

Fig-1: Brain CT without PDCI injection: hypodensity of left capsulo-lenticular region

A complementary assessment was carried out, including normal ultrasound and cardiac Doppler ultrasound and supra aortic trunks, as well as a biological assessment, namely a blood count which showed microcytic anemia (Hb: 3.4g / dl) (VGM: 67 $\mu \mathrm{g})$. ) by iron deficiency (Ferritin: $14 \mu \mathrm{g} / \mathrm{l}$ ) associated with thrombocytosis (PLQ: 624.000/ $/ \mu$ ) without hyperleucocytosis (GB: $7.100 / \mu \mathrm{l}$ ) Rhesus blood group $(\mathrm{A}+)$. Uremia at $0.19 \mathrm{~g} / 1$ and creatinine at $10.77 \mathrm{mg} / 1$, TP at $92 \%$, TCK at 12 seconds.

In the light of these clinical and paraclinical data, the diagnosis of cerebral infarction, complicated by iron deficiency anemia, was made. A treatment was proposed based on antiplatelet platelet aspirin $(100 \mathrm{mg} /$ day) and enoxaparin $40 \mathrm{mg} /$ day preventive dose. Blood transfusion was done with Globular Concentrates during the acute phase and iron injections during the maintenance phase. Treatment that improved the patient's clinical condition after 10 days of hospitalization, the consequences of which were complicated by the occurrence of a retro-placental hematoma that led to a caesarean section and extraction of a stillborn 750 gram. After 26 days of hospitalization the evolution was marked by a good general state of the patient and hemoglobin rate to $10.8 \mathrm{~g} / \mathrm{dl}$. She is entrusted to a neurologist for the follow-up care.
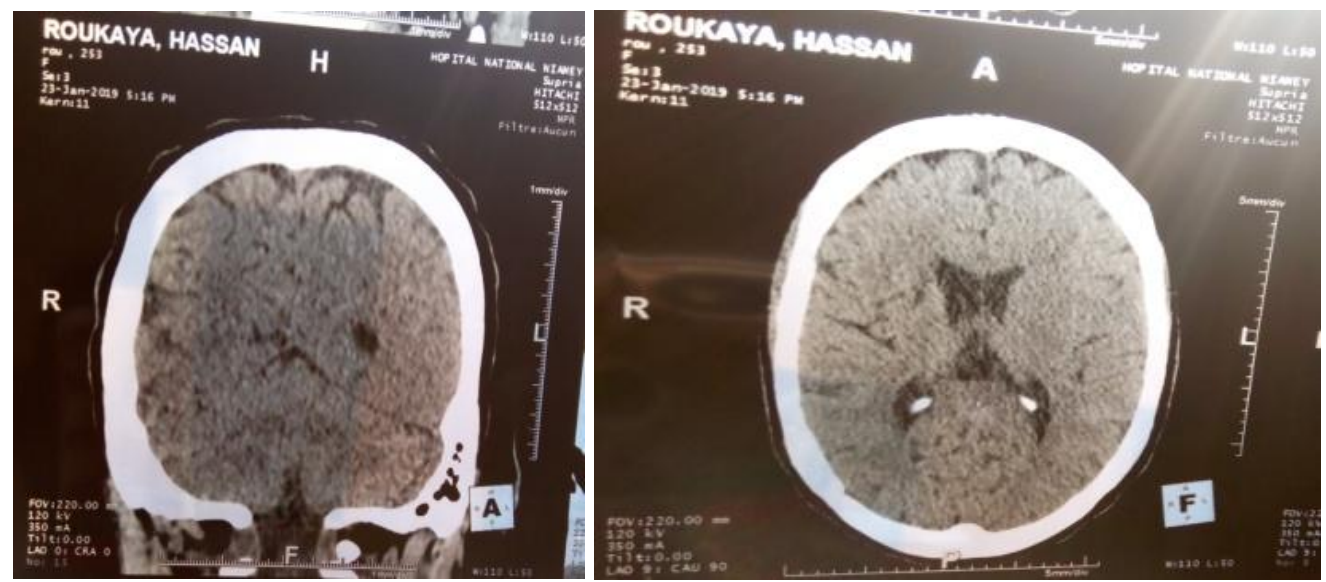

Fig-2: Brain CT without PDCI injection: hypodensity of left capsulo-lenticular region

\section{DISCUSSION}

Cerebral infarction is a very rare pathology. The majority of epidemiological studies on the incidence of stroke-GP are hospital-based, often monocentric [1, 5]. Most focused on small numbers. The incidence of cerebral infarction varies from 4 to $36 / 100000$ pregnancies. According to a recent study published in the international journal of stroke, 30 women / 100,000 are at risk of stroke during pregnancy [6]. This scarcity is undocumented in Niger.

Except for classical vascular risk factors, some authors have described risk factors that are more or less specific to pregnancy: maternal age greater than 35 years, black race, hypertension (hypertension), preexisting or gestational, pre-eclampsia, post complications -partum. Hamel et al., [7], reported a predominance during the third trimester and in the postpartum period. In our observation at age and under 35 , the gestational age was 26 weeks and no cardiovascular risk factors were found. The reported cases of myocardial infarction are more likely to occur in middle-aged women during the third trimester and postpartum. In 20 to $40 \%$ of cases in the literature, the cause of the infarction remains uncertain [4]. We found in our observation iron deficiency anemia associated 
with thrombocytosis. In a few rare cases, arterial or venous cerebral ischemic events have been reported associated with thrombocytosis secondary to splenectomy or iron deficiency anemia [9, 10]. Numerous uncertainties remain as to the therapeutic, neurological and obstetrical care needed. Apart from high thromboembolic pathologies (major emboligenic heart diseases, coagulopathies), the antithrombotic treatment most often proposed in case of cerebral infarction is aspirin. The available recommendations are, however, few [11]. The Canadian Best Practice Stroke Guideline (management of acute stroke during pregnancy, 6th edition, July 2018) is the most recent one. If indicated for anticoagulant therapy, low molecular weight heparins (enoxaparin, dalteparin, tinzaparin) are the treatment of choice because they do not cross the blood-wall barrier. In our observation, the combination of aspirin and enoxaparin at a preventive dose has been successful in terms of maternal prognosis. It is likely that the retro placental hematoma that has marked the obstetric prognosis of our patient is a complication of anticoagulant therapy. Indeed Clouqueur et al., [12]. There was a relative risk of 1.25 in the occurrence of a major haemorrhagic event including retro placental hematoma during aspirin intake during pregnancy, this risk would certainly be increased if aspirin and heparin were combined [12].

\section{CONCLUSION}

Beyond the data on the causes and consequences of the occurrence of a cerebral infarction in the pregnant woman, this case falls within the observational framework but especially the therapeutic planning which is an emergency and must be well codified and instituted by Sudden onset of focal neurologic signs as any delayed diagnosis worsens the maternal-fetal prognosis.

\section{REFERENCES}

1. Lamy, C. (2013). Accident vasculaire cérébral de la grossesse et du post-partum: AVC DU SUJET JEUNE. La Revue du praticien (Paris), 63(7), 933-935.
2. Kuklina, E. V., Tong, X., Bansil, P., George, M. G., \& Callaghan, W. M. (2011). Trends in pregnancy hospitalizations that included a stroke in the United States from 1994 to 2007: reasons for concern?. Stroke, 42(9), 2564-2570.

3. Brenner, B. (2004). Haemostatic changes in pregnancy. Thrombosis research, 114(5-6), 409414.

4. Tang, S. C., \& Jeng, J. S. (2010). Management of stroke in pregnancy and the puerperium. Expert review of neurotherapeutics, 10(2), 205-215.

5. Lamy, C. (2012). Accident vasculaire cérébral et grossesse. La Lettre du neurologue, 16(6), 190194.

6. Helms, A. K., \& Kittner, S. J. (2005). Pregnancy and stroke. CNS spectrums, 10(7), 580-587.

7. Hamel, V., Goubet-Potiron, C., Berthier, F., \& Jenvrin, J. (2015). Régulation médicale de la femme enceinte pour une céphalée brutale. Urgences, $3 ; 8$.

8. Belman, A. L., Roque, C. T., Ancona, R., Anand, A. K., \& Davis, R. P. (1990). Cerebral venous thrombosis in a child with iron deficiency anemia and thrombocytosis. Stroke, 21(3), 488-493.

9. Crassard, I., \& Woimant, F. (2005). Affections hématologiques et accidents vasculaires cérébraux. EMC-Neurologie, 2(3), 339-348.

10. Sacco, R. L., Adams, R., Albers, G., Alberts, M. J., Benavente, O., Furie, K., ... \& Johnston, S. C. (2006). Guidelines for prevention of stroke in patients with ischemic stroke or transient ischemic attack: a statement for healthcare professionals from the American Heart Association/American Stroke Association Council on Stroke: cosponsored by the Council on Cardiovascular Radiology and Intervention: the American Academy of Neurology affirms the value of this guideline. Stroke, 37(2), 577-617.

11. Clouqueur, E., Subtil, D., Robin, G., \& Tsatsaris, V. (2010). Que reste-t-il des indications del'aspirine en cours de grossesse. Journal Gynecol Obstet Biol Reprod, 39:S1-S342

12. Bates, S. M., Greer, I. A., Hirsh, J., Ginsberg, J. S. (2005). Anticoagulant et grossesse. Journal des Maladies vasculaires, 3(2):242. 